\title{
Synthesis and Polymerization of Aminoquinoxaline Derivatives and Their optical Characteristics
}

\author{
Hitoshi Furusho ${ }^{1}$, Akira Yanagimoto ${ }^{1}$, Hisae Miyamoto ${ }^{2}$, Katumi Chikama ${ }^{2}$, \\ Yukio Nagasaki ${ }^{3}$ \\ ${ }^{1 .}$ Nissan Chemical Industries, LTD. Chemical General Division. 3-7-1Kanda \\ Nishikicyo Chiyoda-ku Tokyo, Japan \\ 2. Nissan Chemical Industries, LTD. Analysis Research Department Chemical Research Labo. \\ 722-1. Tsuboi-cho, Funabashi-shi, Chiba, Japan \\ ${ }^{3 .}$ Department of Materials Science, Science University of Tokyo, Noda 278-8510, Japan
}

Key words: aminoquinoxaline, $\square$-conjugated materials, bandgap, electron donor, electron acceptor, light emitting diode

\section{Introduction}

Recently, $\square$-conjugated materials have attracted much attention because of their electronic and optical properties. These properties are dependent on the band structure. Controlling of the bandgap $(\mathrm{Eg})$ is one of the most important factors for their electronic and optical properties. One of the methods to control the band gap is introduction of suitable electron donor / acceptor pair into the same molecule, such as aromatic donor and quinonoid acceptor unit. ${ }^{1), 2), 3)}$ From recent investigations for the D/A compounds, it is reported that heterocycles are promising candidates. ${ }^{4), 55,6)}$

In 1967, Hagenrother, et al reported to prepare poly(quinoxalines) for heat-resistant adhesives materials for aircraft. ${ }^{7)}$ Recently, Markus Janke, et al pointed out a light emitting character of poly(phenylquinoxaline) ${ }^{8)}$ Actually, poly(phenylquinoxaline) film showed excellent emission, at $400-500 \mathrm{~nm}$.

\section{(blue emission).}

In order to improve the fluorescent emitting character for wide range of emission, we started to synthesize new polymer containing quinoxaline moiety as acceptor unit. We focused on aminoquinoxaline because it can be polymerized electronically and the amino group is anticipated as suitable donor.

\section{Experiment}

\subsection{Synthesis of Monomers.}

The synthetic route of monomers is described in Scheme1. Condensation of 1,2-diamino-5-nitroBenzene with 1,2-diketones produced nitro-quino xaline derivatives in $0-65 \%$ yields. Aminoquino xaline derivatives (1a-1c) are obtained by the reduction reaction of the nitroquinoxalines by $\mathrm{Pd} / \mathrm{C}$ in $50-60 \%$ yields.

Polymerization of aminoquinoxalines was carried out via electropolymerization method.

Scheme 1. Synthesis of aminoquinoxalines.
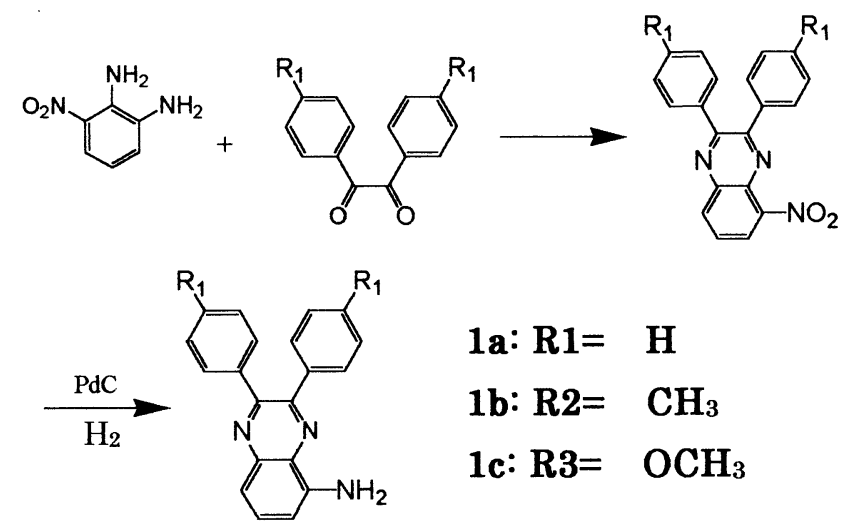

\section{Results and Discussion}

\subsection{Properties of monomers.}

The optical characterization of monomers (1a-1c) is shown in Figs.1 and 2. Energetic level data of these materials is listed in Table 1. The HOMO level was measured by the UPS. The bandgap was 
calculated by the UV spectra.

Table 1. Energetic level data $(1 \mathrm{a}-1 \mathrm{c})$

\begin{tabular}{cccc}
\hline Compound & $\begin{array}{r}\text { HOMO } \\
(\mathrm{eV})\end{array}$ & $\begin{array}{r}\text { LUMO } \\
(\mathrm{eV})\end{array}$ & $\begin{array}{r}\text { Bandgap } \\
(\mathrm{eV})\end{array}$ \\
\hline $1 \mathrm{a}$ & 6.10 & 3.61 & 2.49 \\
$1 \mathrm{~b}$ & 6.50 & 3.86 & 2.64 \\
$1 \mathrm{c}$ & 6.30 & 3.79 & 2.51 \\
\hline
\end{tabular}

The bandgap of the materials was narrowed (about 2.5 $\mathrm{eV})$ by the introduction of amino group to phenylquinoxaline. The amino group was also influenced to the fluorescent emission, viz., monomer 1a-1c showed a $140 \mathrm{~nm}$ red shift compared to 2,3-diphenylquinoxaline. The electron-donating character of the amino lone pair plays an important role for the emission characteristics. On the contrary, the substituents of the benzene rings did not affect the fluorescent emission very much.

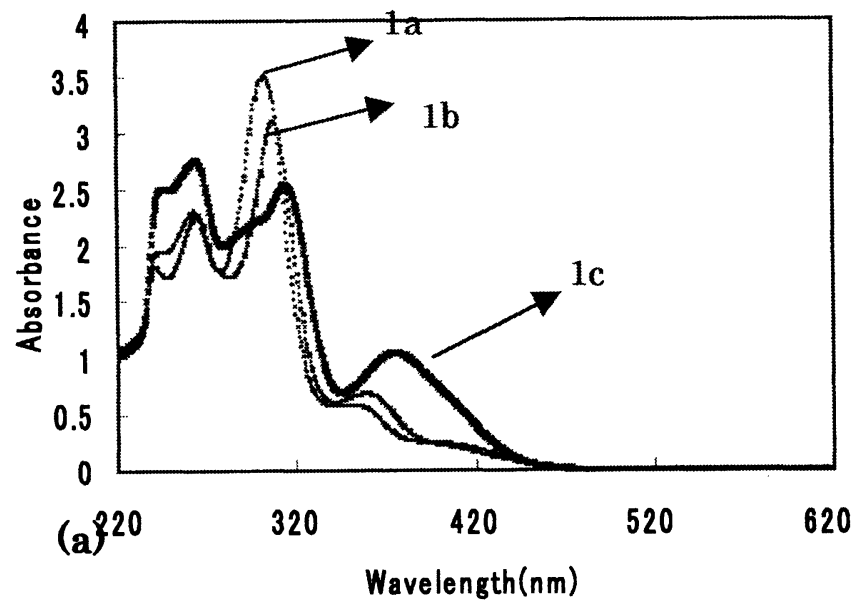

Fig.1. UV-vis spectra of amino(phenylquinoxaline)s in chloroform solution.

\subsection{Properties of polymers.}

Cyclic voltammetry(CV) measurements on monomers 1a-1c were performed using carbon as a working electrode in DMF with $0.1 \mathrm{~mol} \mathrm{dm}^{-3}$ $\mathrm{n}-\mathrm{Bu}_{4} \mathrm{NCl}_{4}$ as the supporting electrolyte(Fig.3). Cyclic voltamogram of monomer $1 \mathrm{~b}$ showed an irreversible oxidation wave. Same behavior was observed by using other monomers. The oxidation peak potentials of the series of monomers vary from 0.51 to $0.54 \mathrm{~V}$ vs. $\mathrm{Ag} / \mathrm{Ag}^{+}$. Polymerization was carried out at same conditions. The polymerization, however, did not proceed at all either on a Pt disk electrode nor in a solvent. CV curve is illustrated in Fig.3(b).]

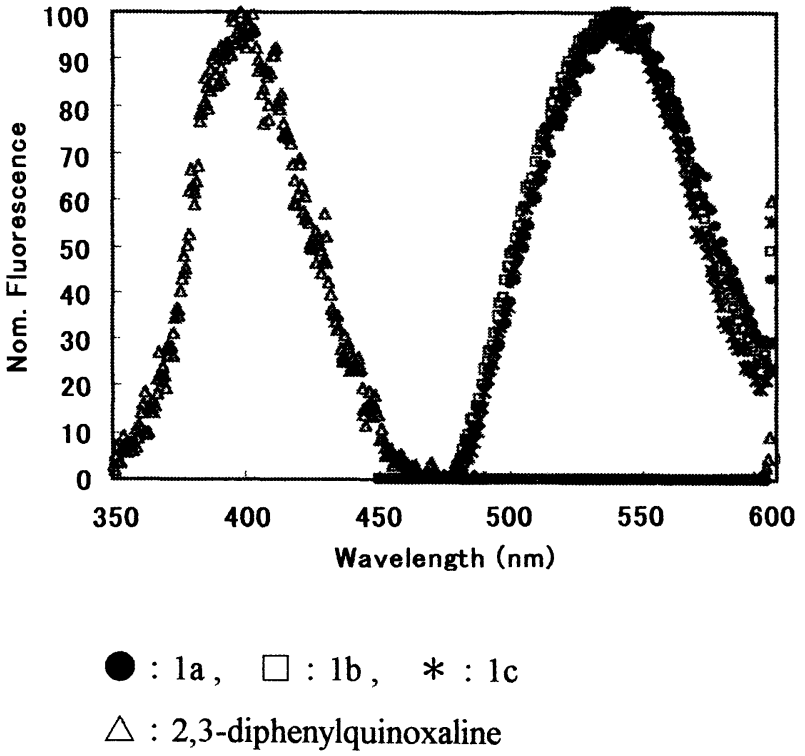

Fig. 2 Normalized fluorescence spectra of amino(phenylquinoxaline)s in chloroform solution
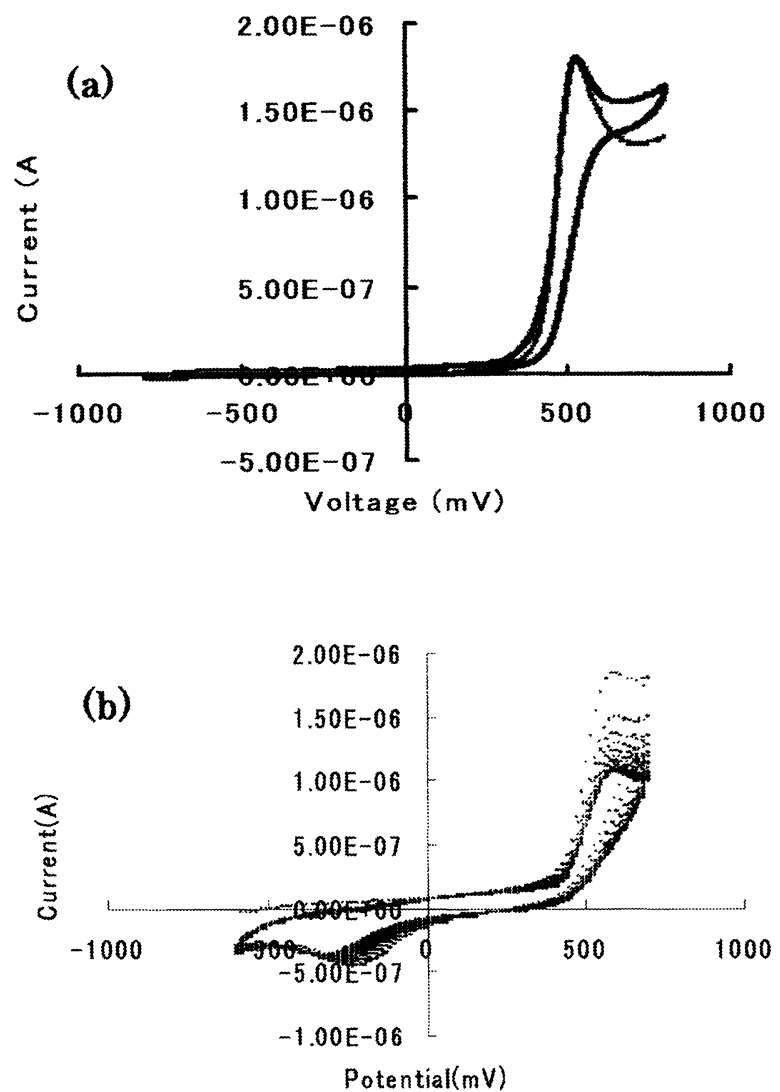

Fig. 3 Cyclic voltammograms

(a) monomer (1b) on Carbon in $0.1 \mathrm{~mol} \mathrm{dm}^{-3}$ $\mathrm{Bu}_{4} \mathrm{NClO}_{4}$ in DMF scan rate $10 \mathrm{mV} / \mathrm{sec}$ (b) 100 cycle (1b) on carbon in $0.1 \mathrm{~mol} \mathrm{dm}^{-3}$ $\mathrm{Bu}_{4} \mathrm{NClO}_{4}$ in DMF, scan rate $10 \mathrm{mV} / \mathrm{sec}$ 
When Indium Tin Oxide (ITO) glass was used under acidic condition, the polymerization took place by the anodic oxidation. The redish-black film was obtained on the ITO electrode. CV curve is illustrated in Fig.4.

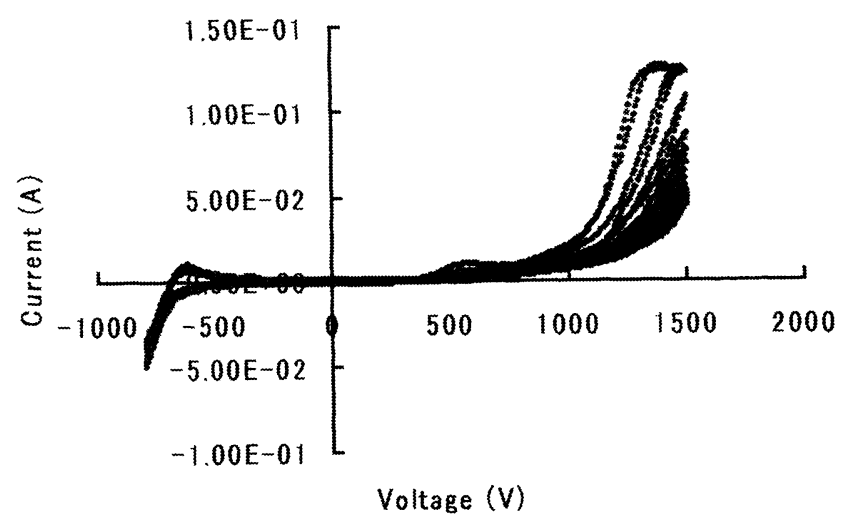

Fig.4 Electropolymerization of amino(phenylquinoxaline) $1 \mathrm{~b}$ $0.55 \mathrm{~mol} \mathrm{dm}-3 \mathrm{HCl}$ in DMF,

Scan rate $100 \mathrm{mV} / \mathrm{sec}$, working electrode ITO vs. $\mathrm{Ag} / \mathrm{Ag}+$

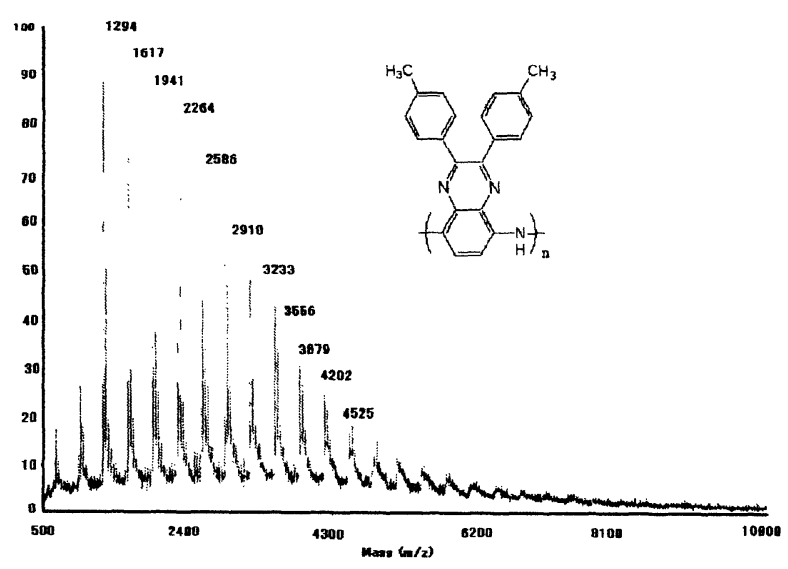

Fig. 5 Mass spectra of $1 \mathrm{~b}$ Polymer.

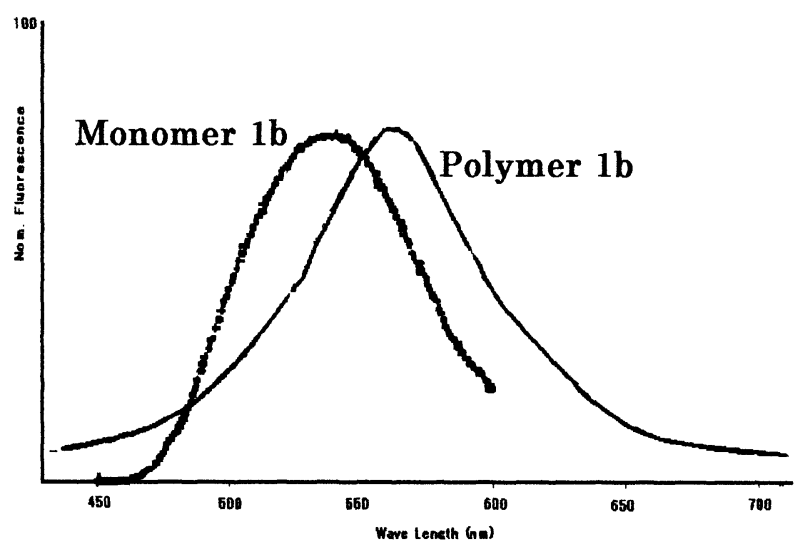

Fig.6 Fluorescence of polymer(1b) in Chloroform $\left(10^{-4} \mathrm{M}\right)$
Molecular weight of the obtained polymer is measured by TOF MS. The result is shown in Fig.5. The fluorescence spectrum of this polymer is shown in Fig. 6. Polymer displays about $14 \mathrm{~nm}$ red-shift compared to the monomer in the fluorescence spectra. The polymer thus obtained was soluble in DMF well despite of short alkyl chain.

Electric properties of the polymer are under investigation and will be published elsewhere.

\section{Conclusion}

A series of monomer composed of amino group (electron-donor) and heterocyclic unit (electron-acceptor) was prepared based on quinoxaline unit. By the introduction of amino group adjacent to quinoxaline unit, the optical properties were greatly influenced. The bandgap of aminoquinoxaline derivatives became narrower $(2.5 \mathrm{eV}-2.6 \mathrm{eV})$ while the substituent in phenyl ring did not affect very much.

The polymerization of amino quinoxaline derivatives proceeded electrochemically to give oligomer having the molecular weight of several hundreds to 5,000 . This is the first example for the electrochemical polymerization of amino-quinoxaline homologues. Fluorescence spectra of the polymer displayed $14 \mathrm{~nm}$ red-shift compared to monomer.

\section{References}

1) S.Tanaka, and Y.Yamashita, Synth. Met., 1995, 69,599-600

2) M.Karikomi, C.Kitamura, S.Tanaka, and $Y$. Yamashita. J.Am.Chem.Soc., $\quad$ 1995, 117, 67916792

3) C.Kitamura, S. Tanaka, and Y. Yamashita, Chem.. Lett., 1996, 63-64

4) J.Kurti, P.R. Surjan, M. Kertesz, and G.Frapper, Synth. Met., 1993, 55-57, 4338

5) J.M. Toussaint and J.L. Bredas, Macromolecules, 1993, 26, 5240

6) J.P.Ferrars, A.Bravo, W.Kim, and D. C. Hrneir, J.Chem.Soc.,Chem. Commun. 1994, 991 7) Hergenrother, P.M. J.Polym. Sci.A-1 1967, 5, 1453

8) Markus Jandke, Peter Strohriegl, Stefan Berleb, Elekkehard Werner, and Wolfgang Brutting, Makromolecules, 1998, 31, 6434-6443 